\title{
Monarquia pluricontinental e repúblicas: algumas reflexões sobre a América lusa nos séculos XVI-XVII *
}

\author{
João Fragoso** \\ Maria de Fátima Silva Gouvếa ${ }^{* * *}$
}

Este artigo corresponde a uma reunião de fragmentos de textos que escrevi com Maria de Fátima Silva Gouvêa, desde 2006. Compõe-se, em sua maior parte, de trechos de projetos de pesquisa apresentados a diferentes agências brasileiras de fomento à pesquisa, ou de publicações que ainda se encontram no prelo. De uma forma ou de outra, são textos inéditos, em que desenvolvemos a ideia de autogoverno, inscrita na concepção corporativa da sociedade, como ferramenta teórica para a compreensão da organização social na América colonial lusa; ou ainda o conceito de redes governativas na gestão do império ultramarino, instrumento de análise caro a Fátima Gouvêa; e concluímos com a noção de monarquia pluricontinental, formulada inicialmente por Nuno Gonçalo Monteiro.

Palavras-chave: Monarquia Lusa na Época Moderna - Império Ultramarino - Elites Coloniais

\footnotetext{
*Artigo recebido e aprovado para publicação em junho de 2009. Este texto foi possível por financiamentos do CNPq, CAPES e Faperj.

** Professor do Departamento de História da Universidade Federal do Rio de Janeiro. Email: jl.fragoso@uol.com.br.

*** Departamento de História da UFF.
} 


\section{Multicontinental Monarchy and Republics: reflections on Portuguese Latin America in the XVI-XVIII century}

This article corresponds to a collection of fragments of the texts I have been writing with Maria de Fátima Silva Gouvêa since 2006. It contains, for the most part, some pieces of the research projects submitted to various Brazilian research promotion agencies, or publications still in the press. Anyway, they are unpublished texts in which we have developed the self-government notion that is part of the corporate concept of society, as a theoretical tool for understanding the social organization in the Portuguese colonial America; or else the concept of government networks during the overseas empire, an analysis tool dear to Fátima Gouvêa; and it is concluded with the notion of multicontinental monarchy originally formulated by Nuno Gonçalo Monteiro.

Keywords: Portuguese Monarchy in the Modern Era-Overseas Empire-Colonial Elite

\section{Monarchie Pluricontinentale et Républiques: quelques réflexions sur} l'Amérique Lusophone du XXI ${ }^{\mathrm{e}}$ au XVIII ${ }^{\mathrm{e}}$ Siècles

Cet article est un recueil de fragments de textes que j’ai écrit avec Maria de Fátima Silva Gouvêa, depuis 2006. Il se compose, en grande partie, de passages de projets de recherche présentés à différentes agences brésiliennes d'incitation à la recherche, ou de publications qui sont encore en cours d'édition. De toute façon, il s'agit de textes inédits ou nous développons l'idée d'autogouvernement, inscrite dans la conception corporative de société, comme outil théorique pour la compréhension de l'organisation sociale en Amérique coloniale lusophone; ou bien encore le concept de réseaux gouvernatifs de gestion de l'empire ultramarin, instrument d'analyse cher à Fátima Gouvêa ; Nous concluons sur la notion de monarchie pluricontinentale formulée initialement par Nuno Gonçalo Monteiro.

Mots-clés: Monarchie Lusophone à l'Époque Moderne - Empire ultramarin Elites coloniales

\section{Para Luigi Gouvêa Tedesco}

No ensaio a seguir procurei reunir algumas passagens de textos que eu e Fátima Gouvêa escrevemos desde 2006. Na sua maioria são trechos de projetos de pesquisa apresentados a diferentes agências brasileiras de fomento à pesquisa ou publicações ainda no prelo. De uma forma ou de outra, são textos inéditos. Neles, temos alguns pontos em comum, tais como: o uso da ideia de autogoverno da concepção corporativa da sociedade enquanto ferramenta 
teórica para a compreensão da organização social colonial na América lusa; o de redes governativas na gestão do império ultramarino (instrumento de análise caro a Fátima); e a ideia de monarquia pluricontinental. Esta última surgiu inicialmente em um texto de Nuno Gonçalo Monteiro ${ }^{1}$ e recentemente eu e Fátima procuramos contribuir na sua formulação. No caso, intuímos que se tratava de uma chave cognitiva capaz de dar conta da dinâmica do império ultramarino português - na expressão de Charles Boxer ${ }^{2}$ - nele incluindo a concepção corporativa (autonomia dos corpos sociais), porém, tendo clara a sua diferença com o conceito de monarquia compósita de J.H. Elliott aplicado para Espanha dos Austrias. ${ }^{3}$

Desnecessário afirmar que este texto, como os demais que escrevi com Fátima, é um "trabalho em progresso" e deste modo ávido por críticas. Aliás, uma das características da proposta do Antigo Regime nos trópicos foi sempre o de procurar o debate teórico decorrente de pesquisas de forte base empírica - estas em curso ou concluídas - e controladas por métodos científicos. Devo que dizer isto é algo que cada vez mais caracteriza a historiografia profissional brasileira. Por seu turno, toda e qualquer responsabilidade sobre os exageros e esquecimentos a seguir são de minha responsabilidade.

\section{$* * *$}

Estima-se que a população da América lusa tenha aumentado de 100.000 em 1600 para 1.500.000 habitantes em 1766. Portanto, em menos de dois séculos tal população cresceu cerca de 15 vezes. ${ }^{4}$ Para o tráfico de escravos, acredita-se que ao longo dos Quinhentos chegaram à mesma América 29.275 africanos e no século seguinte 784.457 cativos; o crescimento fora de mais de 25 vezes..$^{5} \mathrm{O}$ conjunto de tais números sugere o aparecimento de uma verdadeira Babilônia, entendida como confusão, nesta parte do Atlântico Sul, pois, entre aqueles africanos, encontramos pessoas das terras islamizadas do

\footnotetext{
${ }^{1}$ Monarquia pluricontinental é uma fórmula apresentada por Nuno Monteiro no capítulo "A tragédia dos Távora. Parentesco, redes de poder e facções políticas na monarquia portuguesa em meados do século XVIII", Maria de Fátima S. Gouvêa e João L. R. Fragoso (orgs.), Na trama das redes. Política e negócios no império português. Séculos XVI-XVIII, Rio de Janeiro, Civilização Brasileira, [s.d].

2 Trata-se de Charles, R. Boxer, O Império colonial português, Lisboa, Edições 70, 1981.

3 John Elliott, “A Europe of Composite Monarchies”, Past and Present, 137 (nov. 1992).

${ }^{4}$ BRASIL, IBGE, Estatísticas Históricas do Brasil, 2. ed., Rio de Janeiro, 1990, p. 30.

${ }^{5}$ David Eltis; David Richardson; Stephen Berhens; Manolo Florentino, The trans-atlantic slave trade database, disponível em: http://wilson.library.emory.edu:9090.
} 
Senegâmbia, do reino do Daomé, das aldeias dos Ijós do delta Níger e das linhagens matrilineares de Angola. Em outras palavras, homens e mulheres de diferentes sociedades, culturas e idiomas. A essas multidões uniram-se os açorianos, minhotos etc. Com certeza os reinóis e ilhéus comungavam os preceitos da mesma monarquia católica e corporativa, mas não necessariamente partilhavam dos mesmos sistemas e práticas costumeiras de organização familiar e de transmissão de patrimônio.

Apesar desta torre de Babel estar espalhada, no século XVII, ao longo de uma costa de milhões de quilômetros com maior concentração em ilhas de povoamento como o recôncavo baiano, litoral de Pernambuco e cercanias da Guanabara - tão distantes uma da outra como Lisboa de Berlim -, o fato é que ela deu certo. Aquela Babilônia se transformou numa sociedade organizada conforme normas do Antigo Regime (monarquia, catolicismo, ideia de autogoverno etc.) reconhecidas por todos e tendo por base uma economia escravista. Em outras palavras, a dita torre de Babel não foi engolida pela floresta tropical nem virou comida de onças pintadas, de jiboias e nem foi dizimada por epidemias. Como economia ela foi responsável no século XVII pelo sustento desde uma monarquia pluricontinental e de sua nobreza no reino, de Misericórdias, até o pagamento de alforrias e de dotes para várias moças pardas da América; ou ainda, entre 1570 e 1689, o número de engenhos de açúcar passou de 120 para 528, sendo isso acompanhado pela multiplicação de currais, de lavouras de alimentos, de igrejas, de câmaras municipais, de irmandades, de festas etc. ${ }^{6} \mathrm{E}$ tais movimentos foram realizados sem o concurso do capital mercantil inglês e holandês, como ocorreu em Barbados do século XVII em diante. ${ }^{7}$

Da mesma forma, a instalação daqueles engenhos, vilas, escravos, enfim, da população em geral, não contou com a mesma estrutura administrativa do Estado da Índia. Este, na condição de Vice-Reino, possuía conselhos palacianos como Conselho de Estado, Conselho da Fazenda, Casa dos Contos, Casa da Matrícula e Tribunal da Relação e um Tribunal da Mesa da Consciência e Ordens, conselhos consolidados em princípios do século XVI, ${ }^{8}$ isto sem falar

${ }^{6}$ Stuart Schwartz, "The commonwealth within Itself. The Early Brazilian Sugar Industry - 1550-1670", Stuart Schwartz (ed.), Tropical Babylons, University of North Carolina Press, 2004, p.161 e 163.

${ }^{7}$ Robin Blackburn, A Construção do escravismo no Novo Mundo, Rio de Janeiro, Record, 2003; B. W. Higman, “The sugar revolution”, Economic History Review, LIII, 2, 2000, p. 213-236.

${ }^{8}$ Francisco Bethencourt e Kirti Chaudhuri (Dir.), História da Expansão Portuguesa, v. 2, Lisboa, Círculo de Leitores, 1998, p. 304-305 e 320-325. Pedro Cardim terminou de escrever um texto excepcional e inédito para o segundo volume da coleção O Brasil Colonial, onde compara o Estado do Brasil com o da Índia sob o ponto de vista dos seus respectivos sistemas político-administrativos. 
que, para a Índia, consoante a lógica estritamente de Antigo Regime, seguiram até finais dos Seiscentos as integrantes da primeira nobreza, leiam-se, os quadros mais capazes do Reino, enquanto para o Brasil, na mesma época, os fidalgos em geral vinham das Ilhas e possuíam uma menor qualidade. ${ }^{9}$

No século XVII, o Estado do Brasil, apesar do Tribunal da Relação da Bahia, ainda era organizado por uma estrutura administrativa e política precária, bem distante daquela vigente na Índia, e isto numa altura em que, segundo D. Diogo da Silva, marquês de Alenquer,

O Brasil leva todo o este Reino [Portugal] atrás de si bem como as rendas reais porque sem o Brasil não há Angola nem Cabo Verde (...) nem situação em que se paguem às repartições e aos funcionários seus salários, nem meio de que possam viver e dar vida a outros a nobreza, as religiões, as misericórdias e hospitais que tinham nas alfândegas seus rendimentos e tenças. 10

Em contrapartida, no mesmo século, provavelmente, a maior parcela dos gastos da Coroa no ultramar dirigia-se para a Índia.

A combinação destas informações não deve nos assustar, pois fala da lógica de uma monarquia pluricontinental de Antigo Regime; ou seja, apesar de sustentado pelos proventos comerciais ultramarinos, não tinha por lógica ou sentido, se preferirem, um projeto mercantil, mas antes valores afeitos ao Antigo Regime como a defesa da cristandade, o serviço ao príncipe e um ethos aristocrático guerreiro.

Portanto, tentar explicar a formação da sociedade da América lusa através de palavras mágicas ou de ideias como projeto mercantil combinada à coerção da escravidão parece, no mínimo, difícil. Talvez isto fosse possível caso os minhotos, os açorianos e os diferentes africanos tivessem perdidos os seus valores e neurônios na travessia do Atlântico, o mesmo ocorrendo com as populações indígenas. Mesmo caso apelemos para a imagem do Brasil seiscentista como ilhas de canaviais distantes entre si, continua pouco verossímil a ideia de projeto mercantil, pois estes canaviais escravistas teriam de organizar mercados, a produção de alimentos, cuidar de seus doentes, pedir a proteção

${ }^{9}$ Para os titulares dos postos de governo ultramarino, ver Mafalda Soares da Cunha e Nuno Gonçalo F. Monteiro, "Governadores e capitães-mores do império atlântico português nos séculos XVII e XVIII", in: Nuno G. Monteiro, Pedro Cardim e Mafalda Soares da Cunha (org.), Optima Pars. Elites Ibero-Americanas do Antigo Regime, Lisboa, Imprensa de Ciências Sociais, 2005, p. 191-252.

${ }^{10}$ Anais da Biblioteca Nacional do Rio de Janeiro (ABN), 69, 1950, p. 169 citado por Evaldo Cabral de Mello, O negócio do Brasil, Rio de Janeiro, Topbooks, 2003, p. 29. 
dos céus, organizar festas (pois, ninguém era de ferro) etc. Só estes elementos implicavam na existência de entendimentos e de pendengas e, portanto, de instâncias de justiça e de uma ordem social de modo. Neste momento, começamos a construir uma sociedade política, porém, aqui caímos em outro problema: a Coroa, através de seu Governo Geral, não apareceu como um Leviatã nesta América. Assim a questão permanece: como aquela torre de Babel com sua precária administração central se transformou numa sociedade.

\section{$* * *$}

Desde a década de 1970, alguns trabalhos vêm questionando o "esquematismo excessivo" na história do Brasil colônia. No caso, a sociedade brasileira se resumiria em senhores e escravos, e colônia seria um simples corolário da expansão mercantil europeia.

Até fins dos anos de 1980, tal questionamento concentrou-se no estudo das estruturas internas da sociedade colonial brasileira. Tratava-se não de negar a existência do fato colonial, mas sim de não reduzir tudo a ele. Voltados, sobretudo, para o estudo da sociedade escravista, esses trabalhos demonstravam a existência de uma importante autonomia da América lusa frente às conjunturas europeias. ${ }^{11}$ Buscava-se também ampliar o escopo de análise para além da relação metrópole-colônia, visando incorporar a esta também a África, o que era sem dúvida essencial para se compreender uma sociedade escravista. ${ }^{12}$ No entanto, falar em África é também falar de Ásia, já que parte dos circuitos negreiros era abastecida por produtos orientais. ${ }^{13}$

Na década seguinte, esse esforço encontra uma notável correspondência na historiografia internacional, que atravessava também uma importante renovação, particularmente, no tocante aos estudos sobre Estados modernos ${ }^{14}$

${ }^{11}$ Ciro F. S. Cardoso, "Observações sobre o dossiê preparatório da discussão sobre o modo de produção escravista colonial”, in: Charles Parain, Sobre o feudalismo, Lisboa, Editorial Estampa, 1973; João Fragoso, Homens de grossa aventura: acumulação e hierarquia na praşa mercantil do Rio de Janeiro, 1790-1830, Rio de Janeiro, Civilização Brasileira, 1998, 2. ed. (1. ed.: 1992).

${ }^{12}$ Manolo G. Florentino, Em costas negras: uma história do tráfico atlântico de escravos entre África e Rio de Janeiro (séculos XVIII e XIX), Rio de Janeiro, Arquivo Nacional, 1995.

${ }^{13}$ José do Amaral Lapa, A Bahia e Carreira da Índia, São Paulo, Companhia Editora Nacional, 1968.

${ }^{14}$ Antônio M. Hespanha, Às vésperas do Leviathan. Instituições e poder político. Portugal, século XVII, Coimbra, Almedina, 1994; Xavier Gil Pujol, "Centralismo e localismo? Sobre as relações políticas e culturais entre capital e territórios nas monarquias europeias dos séculos XVI e XVII", Penélope: Fazer e Desfazer História, n. 6, Lisboa, 1991; Bartolomé Clavero, Antidora-Antropologia catolica de la economia moderna, Milano, Giuffré, 1990; J. H, Elliott, op. cit. 
e impérios ultramarinos. ${ }^{15}$ Em meio a este debate, a noção de Absolutismo é redefinida e a monarquia passa a ser entendida como a cabeça da república, porém sem se confundir com esta, já que nela existiam outros poderes concorrentes. ${ }^{16}$ Era ela a "cabeça pensante" capaz de articular as jurisdições das várias partes que compunham o conjunto do corpo social, seja no reino, seja no ultramar. A partir desse momento, no caso português, a ideia de um império ultramarino hierarquizado e rígido passa a ser substituído pela de uma monarquia pluricontinental caracterizada pela presença de um poder central fraco demais para impor-se pela coerção, mas forte o suficiente para negociar seus interesses com os múltiplos poderes existentes no reino e nas conquistas.

Para evitar equívocos chamamos de monarquia pluricontinental algo distinto de monarquia compósita. Para Elliott, esta última monarquia - tendo como referência principal o caso espanhol - era algo constituído por vários reinos, com estatutos próprios que preexistiam à formação de tal monarquia. Os vários reinos eram, desse modo, preservados, nos termos de suas formações originais, com seus corpos de leis, normas e direitos locais. Cada uma dessas unidades mantinha sua capacidade de autogoverno no interior de um complexo monárquico mais amplo. Nesse formato, o rei - o monarca - operava como a cabeça do corpo social, constituído pelos vários reinos que se mantinham regidos por suas regras coadunadas com as leis maiores editadas pela Coroa, como era o caso, por exemplo, do Vice-Reino de Portugal e a edição das Ordenações Filipinas em 1602. ${ }^{17}$

A monarquia pluricontinental é aqui entendida de modo bastante diverso. Nela há um só reino - o de Portugal -, uma só nobreza de solar, mas também diversas conquistas extra-europeias. Nela há um grande conjunto de leis, regras e corporações - concelhos, corpos de ordenanças, irmandades, posturas, dentre vários outros elementos constitutivos - que engendram aderência e significado às diversas áreas vinculadas entre si e ao reino no interior dessa monarquia. Ela se constitui, cabe salientar uma vez mais, de modo totalmente diverso daquele descrito por John Elliott em relação à monarquia compósita, visto acima. Tratavam-se, na verdade, na América lusa, por exemplo, de poderes locais - no limite, se organizaram enquanto capitanias - que tomavam

${ }_{15}$ Jack Greene, Negotiated authorities. Essays in colonial political and constitutional history, Charlottesville, University Press of Virginia, 1994.

${ }^{16}$ Antônio M. Hespanha, "O Corporativismo da segunda escolástica”, in: (coord.). História de Portugal - Antigo Regime, v. IV, Lisboa, Ed. Estampa, 1993.

${ }^{17} \mathrm{~J}$. H, Elliott, op. cit. 
instituições sócio-organizacionais reinóis como referência para a formalização de sua organização social.

Outro traço da monarquia pluricontinental, já diversas vezes sublinhado, é que nela a Coroa e a primeira nobreza viviam de recursos oriundos não tanto da Europa mas do ultramar, das conquistas do reino. Trata-se, portanto, de uma monarquia e nobreza que têm na periferia a sua centralidade material.

Cabe ainda sondar como tal monarquia tornava-se realidade. De imediato, ela resultava do processo de amálgama entre a concepção corporativa e a de pacto político, fundamentada na monarquia, e garantindo, por princípio, a autonomia do poder local. A monarquia pluricontinental se torna uma realidade graças à ação cotidiana de indivíduos que viviam espalhados pelo império em busca de oportunidades de acrescentamento social e material; indivíduos que não se colocam passivos diante das regras gerais e que se utilizam das fraturas existentes no permanente diálogo travado entre regras gerais e locais. O mecanismo decisório aqui é totalmente mediado. Traduções e mediações possíveis entre os diversos idiomas se constituem em um processo permanente, possibilitando assim que a vontade de Sua Majestade e de seus vassalos seja de fato preservada e garantida.

Neste ambiente, as redes se configuram enquanto instrumentos privilegiados de ação socioeconômica, capazes de entrecortar - e ao mesmo tempo vincular - cenários tão díspares e por vezes contrastantes na busca de defesa dessa diversidade de interesses; centros e periferias que são conectados através da ação de oficiais da Coroa, como o caso da rede governativa constituída por brokers como João de Lencastre e os César de Meneses, ${ }^{18}$ de grupos mercantis, de irmandades religiosas e de caridade, pela Inquisição, e mais uma infinidade de outros institutos. Mecanismos esses que, conhecidos por todos - tais como os canais de comunicação formal viabilizados pelas câmaras, pelos oficiais da justiça do rei no ultramar, dentre outros -, eram constantemente utilizados para reforçar poderes, posições e interesses que interligavam esses indivíduos pelos mais diversos rincões do império.

Ainda no interior da ideia - mais geral e sistêmica - de monarquia pluricontinental, outra questão tem dinamizado este debate historiográfico, qual seja: o estudo das especificidades e diferenças das diversas áreas ultramarinas que compunham o vasto império português entre os séculos XVI e o XVIII. Referimo-nos à interferência das repúblicas - câmaras - na dinâmica política ${ }^{18}$ Maria de Fátima S. Gouvêa, "Redes governativas e centralidades régias, ca. 1680-1730", capítulo publicado neste livro. 
e econômica do império luso entre os séculos XVI e XVIII. Parte-se aqui do pressuposto de que a organização do império luso da época foi presidida por concepções de monarquia (universus) e de autogoverno das comunidades (república).$^{19}$ Por isso, é cada vez mais importante olhar com cuidado o estudo do governo das gentes nos concelhos camarários. Tal é o caso do governo do Rio de Janeiro, Salvador, Olinda e a sua interferência no modo de ser do império luso. Em outras palavras, é necessário analisar a atuação das câmaras municipais, estas entendidas como responsáveis pela administração cotidiana do abastecimento, do comércio externo e da justiça ordinária. Da mesma forma, em tais repúblicas deve-se atentar para a possibilidade da formação de hierarquias sociais costumeiras, cujas normas podiam ser respeitadas e protegidas pela monarquia. No caso da América lusa, uma destas estratificações era constituída por senhores de engenhos, Donas, fidalgos, negociantes, pardos e escravos. Repare-se que expressões como Donas e $\operatorname{pardos}^{20}$ não eram na América classificações dadas pela Coroa, como o de fidalgo da casa real ou de cavaleiro da ordem de Christo. O príncipe não auferia a uma mulher o título de Dona no Rio de Janeiro e nem classificava um homem de pardo; estas eram prerrogativas, nas repúblicas americanas, de suas gentes, e com isto elas ordenavam uma dada estratificação social.

Há menos de dez anos atrás, provavelmente, o tema autogoverno das comunidades e suas negociações com o centro causaria surpresa no meio acadêmico. Porém, trabalhos recentes como de Annick Lempérière, ${ }^{21}$ por exemplo, lembram que eram as repúblicas, ibéricas ou americanas, que arcavam com o grosso da despesa de sua própria fundação e posterior gestão, posto que os impostos régios iam para a Coroa. À exceção dos gastos com a defesa militar, só muito marginalmente os recursos da Fazenda Real eram aplicados em prol

${ }^{19}$ Para a segunda escolástica ver Quentin Skinner, As fundações do pensamento político moderno, São Paulo, Cia. das Letras, 2006, especialmente p. 432 - 441.

${ }^{20}$ As expressões Dona e pardo foram recolhidas dos registros paroquiais de batismo do Rio de Janeiro entre 1640 e 1760, ao menos. Elas eram utilizadas pelo padre da freguesia para classificar segmentos da população paroquiana. Dona, na região e período considerados, era usado para designar mulheres de antigas famílias locais, em geral descendentes dos conquistadores da região e com passagem nos postos honrosos da governança da terra. Pardo aludia a forros ou egressas da escravidão. Para o caso de pardo consultar a argumentação de Hebe Castro para o século XIX, Das Cores do Silêncio, Rio de Janeiro, Arquivo Nacional, 1993. Ver João Fragoso, "Capitão João Pereira Lemos e o cabra José Batista: notas sobre uma hierarquia social rural costumeira nas freguesias rurais do Rio de Janeiro, século XVIII" (texto inédito).

${ }^{21}$ Annick Lempérière, Entre Dieu et le roi, la République. Mexico, XVIe - XIXe siècles, Paris, Les Belles Lettres, 2004. 
do sustento das comunidades, as quais eram mantidas pelas arrecadações municipais, pela caridade da Igreja e pela fazenda dos vizinhos.

A mesma autora sublinha também, com base na experiência seiscentista mexicana, que as relações entre o centro e a periferia na América tiveram certas particularidades diante do vivido no velho continente. No Novo Mundo não ocorreu o estabelecimento do estado aristocrático e, portanto, nele não encontramos senhorios jurisdicionais. Assim, a sociedade americana tinha em seu topo o príncipe e em sua base as comunidades, as câmaras (os concelhos camarários). Grosso modo, a gestão política da sociedade americana era feita a partir dessas duas instituições.

No caso das conquistas ultramarinas portuguesas, a hipótese do autogoverno das comunidades vem adquirindo uma base empírica mais sólida por meio de pesquisa ainda em curso, intitulada A monarquia e seus idiomas: corte, governos ultramarinos, negociantes, régulos e escravos no mundo português (sécs. $X V I-X I X) .{ }^{22}$ Os resultados parciais e, portanto, sujeitos à mudança tendem a demonstrar que os temas relativos à gestão do cotidiano da sociedade colonial não eram tratados com frequência na correspondência entre o ultramar e a Coroa. Poucas vezes assuntos como comércio, abastecimento (custo de vida, produção e comércio de alimentos), gestão da justiça ordinária, preservação da ordem hierárquica e saúde pública aparecem nas missivas trocadas pelas conquistas ultramarinas e o príncipe. Além disso, a câmara não aparecia com frequência como uma possível interlocutora, quer nas cartas oficiais enviadas, quer nas recebidas do reino. Aparentemente, os temas mais comuns eram os que diziam respeito à ordem militar, à ação e aos desmandos dos agentes administrativos e aos pedidos de mercês. Sobre os interlocutores, estes eram frequentemente o governador, os oficiais régios, as viúvas e os soldados, dentre outros.

Insistimos que os indícios acima são parciais, daí o impressionismo da sua apresentação e, portanto, o cuidado que devemos ter com eles. De qualquer forma, acreditamos que uma das maneiras de se perceber as relações

\footnotetext{
${ }^{22}$ Projeto em curso financiado pelo convênio CAPES-FCT. João Fragoso e Isabel Guimarães, A Monarquia e seus Idiomas: corte, governos ultramarinos, negociantes, régulos e escravos no mundo português (sécs. XVI-XIX), 2007. Este projeto estuda as relações entre o centro e a periferia da monarquia pluricontinental lusa, entre outros meios, pelas correspondências trocadas entre os domínios lusos do Atlântico Sul, nos locais onde existiam câmaras municipais, e o centro através principalmente da documentação depositada no Arquivo Histórico Ultramarino. Foram escolhidas, inicialmente, as câmaras do Rio de Janeiro, Salvador, Olinda, de São Tomé e Luanda (Angola), entre os séculos XVI e XVIII.
} 
entre conquistas e centro é através de pesquisas que permitam medir com alguma precisão o grau de interferência da chamada metrópole no quotidiano das conquistas. Daí o estudo das comunicações políticas entre os domínios do Atlântico Sul e luso e o Reino. Atentos a isto, continuemos a construir as nossas hipóteses.

Apesar do pouco espaço que ocupavam no interior da correspondência oficial que tramitou pelo Conselho Ultramarino no período enfocado (século XVI ao XVIII), temas como ordenamento do mercado, abastecimento, justiça e hierarquia social eram certamente assuntos permanentes - cotidianos - das pautas de gestão das comunidades ultramarinas. Entretanto, isto era tratado, provavelmente, em fóruns como as câmaras e discutidos nas freguesias por potentados e párocos. Depois, se fosse o caso, eram enviadas aos governadores e aos conselhos palacianos do reino. A gestão do quotidiano - e com isto a transformação da torre de Babel em sociedade - era providenciada, em grande medida, no âmbito da república; ou seja, nas instituições locais, tais como os concelhos camarários, as ordenanças, as irmandades, dentre outros. E tudo isto feito consoante a concepção de mundo corporativa e, portanto, com a benção da monarquia e da Igreja.

Uma vez identificada a importância do autogoverno, cabe sublinhar a interferência da república na gestão dos assuntos que diziam respeito às esferas mais amplas e gerais do império como um todo. Para tanto, basta lembrar a frota organizada pelos potentados locais de Salvador, na Bahia, para auxiliar no esforço da Coroa em resgatar Mombaça dos arábicos, em fins do século XVII, assim como os donativos aprovados pelos homens bons reunidos em câmara e enviados pelas comunidades, como a do Rio de Janeiro, por ocasião da luta contra os holandeses no século XVII. Estes donativos viabilizaram, dentre outros eventos, a reconquista de Pernambuco e Angola. ${ }^{23}$

Esta linha de raciocínio demonstra que o entendimento da dinâmica imperial portuguesa e, em particular, das formas de organização social das gentes que nele viviam, necessita de um renovado esforço de pesquisa acerca da organização político-administrativa das repúblicas, assim como o estudo mais acurado das câmaras, das ordenanças, das irmandades e dos capitães de freguesias etc. E isto implica em recuperar e organizar os documentos dos

\footnotetext{
${ }^{23}$ No caso da discussão de Mombaça na câmara da Bahia fora um dos últimos temas investigados por Fátima. Sobre os donativos, ver Boxer, op. cit., João Fragoso, "Nobreza principal da terra do Rio de Janeiro e o Atlântico (1600-1750)”, in: José D. Rodrigues (org.), Poder local, cidadania e globaliæação, Açores, [s.n.], 2007.
} 
arquivos municipais. Por exemplo, para o Rio de Janeiro, pouco se sabe sobre a documentação relativa aos almotacéis e muito menos sobre a registrada pelos escrivães das câmaras. Entretanto, sabe-se, conforme as Ordenações do Reino, que a primeira tinha por incumbência relatar o movimento de abastecimento das cidades; sem esquecer que a cidade do Rio de Janeiro era um dos principais centros do comércio do Atlântico sul no século XVIII. Sobre a segunda, trata-se da memória dos atos públicos da república que fora sede da Repartição Sul em parte do século XVII.

Além do exposto, percebe-se que o estudo das gentes das repúblicas como atores sociais em suas vidas e na dinâmica imperial tem também um cunho metodológico; ou seja, o de enfatizar a chamada micro-história italiana como opção de investigação para o estudo do império luso.

Vale insistir que essa reorientação de abordagem, na qual a ideia de república se encontra diretamente relacionada à de autogoverno, constitui-se em estratégia para um melhor entendimento das formas pelas quais o império era gerido a partir de diversos níveis de interferência cotidiana das várias sociedades ultramarinas que o integravam. Isso coloca os arquivos municipais numa posição chave em termos da pesquisa da História Colonial, bem como do império ultramarino português em seu conjunto, na medida em que tais arquivos são os depositários legais da documentação e, portanto, da memória daquelas repúblicas e de suas relações com tudo que dizia respeito aos rumos do império. Porém, tal importância não corresponde ainda a um esforço de organização das suas fontes e muito menos à existência de um acurado sistema de ferramentas de pesquisas para a viabilização e agilização da investigação do governo das gentes. ${ }^{24}$

Uma vez entendida que na base da América lusa existiam repúblicas, um ponto a ser investigado é como tais repúblicas se conectavam. Além delas estarem sob a tutela de um Governo Geral até o século XVIII, elas partilhavam a mesma concepção de mundo. No caso, elas se sentiam pertencendo à mesma monarquia e nela viam a responsabilidade de cuidar do bem comum das gentes e dirimir conflitos. Um outro ponto que talvez também servisse de conexão eram as redes sociais e parentais tecidas pelas elites locais para além de seus municípios e mesmo capitanias.

\footnotetext{
${ }^{24}$ Nos últimos anos, Departamentos de História de diferentes universidades federais vêm organizando os acervos das câmaras municipais. Entre eles, temos o da UFOP e o de São João Del Rey.
} 
Um exemplo disto foram os movimentos de conquista de frações de famílias paulistas para o Rio de Janeiro e de pernambucanas para outras áreas do Norte, chegando até à conquista do Maranhão. No Rio de Janeiro, por exemplo, uma das consequências da conquista da Guanabara foi o estabelecimento por frações de elites paulistas como os Aires Aguirre e os Amaral. Em finais do primeiro quartel do século XVII temos fluxos de personagens das elites locais do Rio para o Norte e vice-versa. Um bom exemplo disto foram os pactos entre os Gago da Câmara, os Soutomaior (ambos do Rio) e os Albuquerque Maranhão (de Pernambuco) ou dos Correia Vasqueanes com potentados da Bahia. Em 1645, Izabel da Câmara, filha de Pedro de Gago da Câmara - Capitão da Fortaleza de Santa Cruz, no Rio - casou-se com Matias de Albuquerque Maranhão, neto de Jerônimo de Albuquerque - Governador do Maranhão em 1614 - e futuro Governador da Paraíba, em 1657. Na geração seguinte, Apolônia, filha de Isabel e Matias, esposou seu primo-irmão André Gago da Câmara. André era filho de uma Silveira Soutomaior e uma de suas irmãs se tornaria esposa, em 1679, de outro primo-irmão: Francisco da Silveira Soutomaior, que fora Ouvidor-Sindicante do Rio e Desembargador no Tribunal da Relação da Bahia, em 1680. Completando estas alianças suprarregionais, temos os três casamentos de Salvador Correia Vasqueanes, filho do velho Governador Duarte Vasqueanes, e também integrante dos Teles/Correia: o primeiro, em c. 1659, com a descendente de João Pais de Barros, antigo Governador de Pernambuco, entre 1619 e 1620; o segundo, em 1676, com a filha do Mestre de Campo na Bahia e futuro Governador do Rio, Pedro Gomes; em 1679, com uma parenta do Chanceler da Relação da Bahia, entre 1667 e 1680, João de Araújo Góes. ${ }^{25}$

\section{$* * *$}

A confluência entre o tema monarquia pluricontinental e as repúblicas na América leva-nos a discutir o estatuto da conquista. Como afirma Pedro Cardim,

\footnotetext{
${ }^{25}$ Antônio de S. M. Jaboatão, "Genealogia Baiana”, Revista do Instituto Histórico e Geográfico Brasileiro, v. 191, Rio de Janeiro, IHGB (org. por Afonso Costa), Jaboatão, 1946, p. 13-57; João Fragoso, "A nobreza vive em bandos: a economia política das melhores famílias da terra do Rio de Janeiro, século XVII", Tempo - Revista do Departamento de História da UFF, Niterói, v. 8, n. 15, p. 11-35, 2003; João Fragoso, "Nobreza Principal da Terra do Rio de Janeiro e o Atlântico (1600-1750)", in: José D. Rodrigues (org.), Poder local, cidadania e globaliæação, Açores, [s.n.], 2007.
} 
os domínios extraeuropeus das Coroas Ibéricas foram tratados como "conquistas" (...) [resultando] sérias consequências quanto aos direitos políticos gozados pelas suas instituições e pelos seus habitantes: eram territórios escalonados numa posição inferior face aos domínios europeus das Coroas ibéricas, estando as suas populações desprovidas de alguns dos mais substantivos direitos políticos, como por exemplo a "honra" de tomar parte na assembleia de Cortes. ${ }^{26}$

Mesmo considerando que os municípios do próprio reino não manifestavam grande interesse em participar das Cortes, como nos ensina ainda Pedro Cardim, ${ }^{27}$ o fato é que os moradores da conquista tinham uma menor qualidade do que os reinóis. Esta é uma questão delicada, pois pressupõe trabalhar também com a visão que tais moradores faziam de si e como eles eram tratados por sua majestade. Vejamos como as elites locais da conquista percebiam tais questões. Como se sabe, Jerônimo de Albuquerque e Maranhão, mestiço natural de Pernambuco, se via e era reconhecido pelo reino como capitão-mor da conquista do Maranhão. ${ }^{28}$ Em 1732, Julião Rangel de Sousa Coutinho, como procurador do senado da câmara do Rio de Janeiro, encaminhava ao rei uma carta na qual denunciava a interferência de oficiais régios nas eleições municipais e ao mesmo tempo sublinhava que os cargos honrosos da república pertenciam "aos filhos e netos dos cidadãos descendentes dos conquistadores daquela capitania, de conhecida e antiga nobreza, e de nenhuma sorte os netos e descendentes de oficiais mecânicos ou de avós de inferior condição, sem embargo de que alguns por possuírem cabedais estejam vivendo a lei da nobreza". ${ }^{29}$

Em outras palavras, Julião Rangel entendia a condição de descendente de conquistador não como condição de menor qualidade, mas como prerrogativa de mando. Ele e demais descendentes de conquistadores e demais moradores da capitania compartilhavam de uma hierarquia social costumeira cujo eixo era a conquista e a organização da república em um domínio extraeuropeu.

Assim estes sujeitos se valiam dos serviços de conquista à sua majestade para acrescentar honra as suas casas e deste modo pretendiam alterar o signi${ }^{26}$ Pedro Cardim, Entre o centro e as periferias, in: Mafalda Soares da Cunha, Os Municípios no Portugal Moderno, Évora, CIDEHUS/Edições Colibri, [s.d.], p. 214.

${ }^{27}$ Idem, ibidem, p. 221.

${ }^{28}$ Frei Vicente Salvador, História do Brasil, Belo Horizonte, Itatiaia/ São Paulo, Ed. da USP, 1982, p. 337.

${ }^{29}$ AHU, Ca., RJ, cx. 34, doc. 7550, 1732. Carta do procurador do senado Julião Rangel de Sousa Coutinho contra a interferência dos ministros nas eleições do senado. 
ficado da sua qualidade. Em outras palavras, eles se viam não como simples moradores em território extraeuropeu, mas como conquistadores destes territórios. Como afirmamos acima, eles não eram sujeitos passivos diante das regras. Eles, na verdade se valiam, como ensina F. Barth, ${ }^{30}$ das fraturas do sistema normativo da monarquia. Considerando esta possibilidade, talvez seja possível entender o porquê das famílias que participaram da conquista e organização da sociedade nos territórios ultramarinos se virem não como vassalos de segunda categoria mas como conquistadores e, portanto, merecedores de privilégios diante do príncipe.

Monarquia pluricontinental, redes governativas, repúblicas americanas, o estatuto dos homens da conquista, a transformação de uma torre de Babel numa sociedade, estes e outros temas faziam parte dos vários projetos de pesquisa de Fátima Gouvêa... E a vida que segue.

${ }^{30}$ Fredrik Barth, Process and form in social life, v. 1, London, Routlegde \& Kegan Paul, 1981, p. 32-60. 